\title{
Sesquiterpenes from Cupressus macrocarpa foliage
}

Laurence G. Cool

University of California College of Natural Resources, 1301 S. 46th St.,

Richmond, CA 94804, USA

Ten new sesquiterpenes, many of them with novel carbon skeletons, were identified

in foliage of Cupressus macrocarpa. Their possible single-enzyme biosynthesis is discussed.

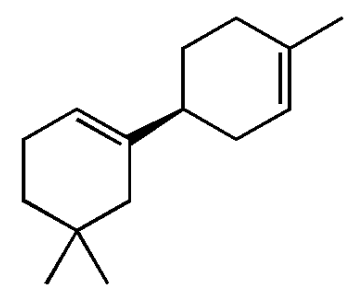




\title{
Sesquiterpenes from Cupressus macrocarpa foliage
}

\author{
Laurence G. Cool* \\ University of California College of Natural Resources, 1301 S. 46th St., Richmond, CA 94804, USA \\ Received 2004; accepted 2004
}

* Current address: 2408 McKinley Ave., Berkeley, CA 94703, USA. Tel.: + 1-510-549-3972

E-mail address: larry.cool@sbcglobal.net 


\begin{abstract}
Ten new sesquiterpenes, many of them representing novel carbon skeletons, were identified in foliage of Cupressus macrocarpa. These are (-)-10-epi- $\beta$-acoradiene; entwiddra-2,4(14)-diene; $(E)$-iso- $\gamma$-bisabolene i.e. (4E)-4-(1,5-dimethylhex-5-enylidene)-1methylcyclohexene; (-)-cumacrene i.e. $(4 S)-4-[(1 R, 2 S)$-2-isopropenyl-1methylcyclobutyl]-1-methylcyclohexene; (-)- $\alpha$-chamipinene i.e. $(1 S, 6 S, 7 S)-2,2,6,8$ tetramethyltricyclo[5.3.1.0 $\left.0^{1,6}\right]$ undec-8-ene; and five sesquiterpenes with a 3,3,4'trimethyl-1,1'-bi(cyclohexyl) skeleton for which the trivial name macrocarpane is proposed. The possible single-enzyme biogenesis of these sesquiterpenes is discussed.
\end{abstract}

Keywords: Cupressus macrocarpa; Cupressaceae; Monterey cypress; Foliage; Sesquiterpenes; Macrocarpene; Cumacrene; $\alpha$-Chamipinene; epi- $\beta$-Acoradiene; entWiddradiene; iso- $\gamma$-Bisabolene. 


\section{Introduction}

Cupressus macrocarpa Hartw. ex Gord. (Monterey cypress) is a narrow endemic native only on Point Lobos and Cypress Point, Monterey Co., California. It is a large and picturesque tree, and despite its limited natural range it is one of the best-known and most widely planted conifers in the state.

Within Cupressus, Monterey cypress has been considered most closely related to four other coastal Californian cypress taxa with non-glandular foliage: C. abramsiana C. B. Wolf, C. goveniana ssp. goveniana Gord., C. goveniana ssp. pygmaea (Lemm.) Bartel, and C. sargentii Jeps., although Wolf (1948) saw it as morphologically somewhat distant from the others. The distinction of C. macrocarpa within this north-coastal group of cypresses was supported by analysis of their foliar monoterpene composition (Zavarin et al., 1971).

All of the north-coastal Cupressus species produce an essential oil that is low in sesquiterpenoids (Zavarin et al., 1971). Briggs and Sutherland (1942) analyzed $C$. macrocarpa foliar oil by fractional distillation and reported only ca. $0.7 \%$ for the sesquiterpene fraction of the oil. Our examination of 40 C. macrocarpa specimens (20 planted and 20 from the Point Lobos population) by gas chromatography-mass spectrometry (GC-MS) confirmed that sesquiterpenes are generally a minor component of the volatile oil. However, some individuals produced oil with up to $9 \%$ sesquiterpenoids, which included a number of apparently novel hydrocarbons. The 
identity of ten of these sesquiterpenes is the subject of this report.

\section{Results and discussion}

A number of sesquiterpenoids were ubiquitous in Cupressus macrocarpa foliage, though in widely varying amounts: $\alpha$-cubebene, $\beta$-funebrene, caryophyllene, germacrenes A and B, cedrol, $\alpha$-bisabolol, nerolidol, and farnesol were detected by GCMS in nearly all trees. There was also a distinct chemophenotype, represented in three of the 40 trees, which produced sizable amounts of germacrene $\mathrm{C}$ (detected as the Cope rearrangement product $\delta$-elemene), $(+)$-guaia-6,9-diene 1 , and an unknown that is tentatively identified as $(1 R, 4 S, 5 R)$-guaia-6,10(15)-diene $\mathbf{2}$ (see Experimental). The chirality of 1 was determined from its retention time on enantioselective GC (EGC hereinafter), which was different from that of authentic (-)-guaia-6,9-diene. $(+)-$ Guaia-6,10(15)-diene has been reported from the coral Nephthea chabrolii (Rao et al., 2000), though the absolute stereochemistry was not determined. The absolute stereochemistry of putative $\mathbf{2}$ from C. macrocarpa is assumed to be the same as $\mathbf{1}$.

A second, and more common, C. macrocarpa chemotype (29 of 40 trees) was typified by presence of over 25 unknown sesquiterpenes, ten of which were in sufficiently high concentration for isolation and characterization. Known compounds $(-)-\beta$ sesquiphellandrene, $\delta$-cuprenene, acora-3,7- and -4,7-diene (Kaiser and Naegeli, 1972; Marx and Norman, 1975), (-)-dauca-8,11-diene (Cool, 2001), and the rare (-)cuparene and (-)- $\alpha$-cuprenene, were also detected in small amounts during isolation of 
the major sesquiterpenes in the oil.

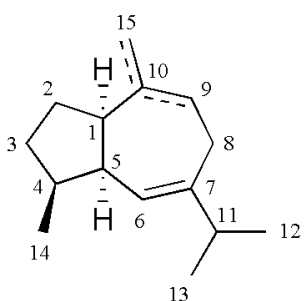

$1 \Delta^{9}$

$2 \Delta^{10(15)}$

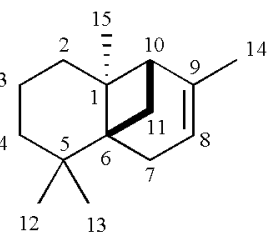

11

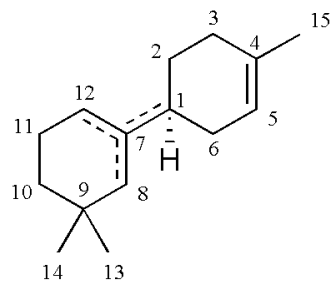

$3 \Delta^{7}$

$4 \Delta^{7(12)}$

$5(Z)-\Delta^{1(7)}$

$6(E)-\Lambda^{1(7)}$

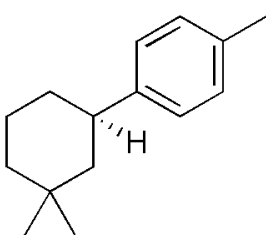

7

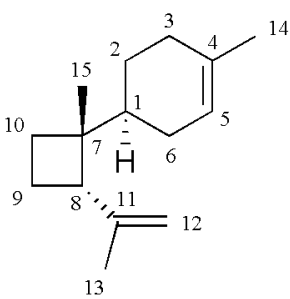

8

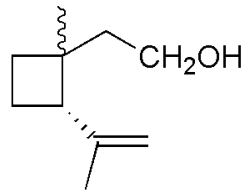

$9 \beta \mathrm{Me}$ $10 \propto \mathrm{Me}$

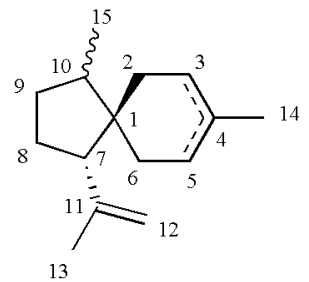

$12 \Delta^{3}, 10 \alpha \mathrm{Me}$ $13 \Delta^{4}, 10 \beta \mathrm{Me}$

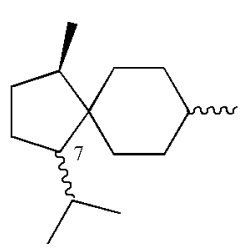

14a/b $7 \alpha$ isoPr 14c/d $7 \beta$ isoPr

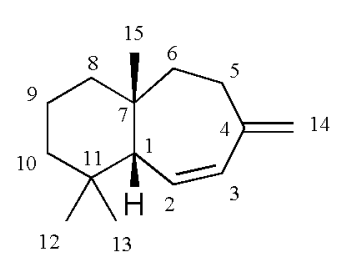

15

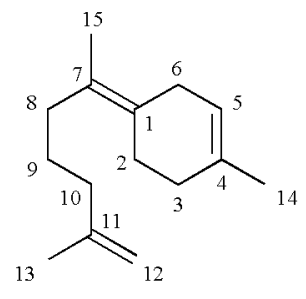

16

Compounds 3-7 proved to be irregular sesquiterpenes with a 3,3,4'-trimethyl-1,1'(bicyclohexyl) skeleton, for which the trivial name macrocarpane is proposed. Greek letters and $a r$-, $E$ - and $Z$ - prefixes indicate the various double-bond and geometric macrocarpene isomers (see Experimental). These sesquiterpenes are remarkable in having only three terminal carbons, the fourth having presumably been incorporated during biogenesis of the dimethylcyclohexane ring.

The structures of $\alpha$ - and $\beta$-macrocarpene (3 and $\mathbf{4}$ ), which were the major sesquiterpenes in this chemotype, were deduced from the 1D NMR data (see Experimental). The ${ }^{1} \mathrm{H}$ 
and ${ }^{13} \mathrm{C}$ spectra of both included seven signals almost identical to those of the corresponding non-isopropenyl atoms of limonene, while other ${ }^{1} \mathrm{H}$ signals of $\mathbf{3}$ and $\mathbf{4}$ closely matched data for the ring protons of 1,3,3- and 1,5,5-trimethylcyclohexene, respectively (Snowdon et al., 1987). HMQC experiments permitted assignment of all ${ }^{1} \mathrm{H}$ and ${ }^{13} \mathrm{C}$ signals, and an $\mathrm{HMBC}$ experiment on $\mathbf{4}$ confirmed the macrocarpane carbon skeleton (correlations in Table 1).

Both 3 and 4 are levorotatory, and based on studies on the optical rotation of 4substituted 1-methylcyclohexenes (Mills, 1952), their absolute stereochemistry can be assumed to be that of (-)-limonene, i.e. $1 S$.

The structures of non-chiral double bond isomers $(Z)$ - and $(E)-\gamma$-macrocarpene $(\mathbf{5}$ and $\mathbf{6}$ respectively), which occur in ca. 1:5 ratio in the oil, were inferred from their ${ }^{1} \mathrm{H},{ }^{13} \mathrm{C}$, ${ }^{1} \mathrm{H}-{ }^{1} \mathrm{H}$ NOESY, and (for 5) HMBC NMR data (see Table 1). The spectra of 5 and $\mathbf{6}$ were very similar and absence of a chiral center in these compounds was evident from magnetic equivalence of the ${ }^{1} \mathrm{H}$ or ${ }^{13} \mathrm{C}$ signals from both atoms of each geminal pair. NMR data of terpinolene $\left({ }^{1} \mathrm{H}\right.$ and $\left.{ }^{13} \mathrm{C}\right)$ and 3,3-dimethylmethylenecyclohexane $\left({ }^{1} \mathrm{H}\right.$; Bernard et al., 1974) had the pertinent methyl and ring signals very close to those of 5 and 6. The macrocarpane carbon skeleton of the predominant $E$ isomer $\mathbf{6}$ was confirmed by hydrogenation, which yielded the same two isomeric $M_{r}=208$ compounds as were obtained from hydrogenation of 4 . The geometry of the tetrasubstituted double bond was determined by NOESY experiments, in which the decisive cross-peaks were 
Table 1

${ }^{13} \mathrm{C}$ NMR and ${ }^{1} \mathrm{H}$ data ${ }^{\mathrm{a}}$ of macrocarpenes 3-6, $\delta$ from $\mathrm{TMS}^{\mathrm{b}}$

\begin{tabular}{|c|c|c|c|c|c|c|c|c|c|c|c|c|}
\hline \multirow[b]{2}{*}{$\begin{array}{c}\mathrm{C} \\
\text { No. }\end{array}$} & \multicolumn{2}{|r|}{$3\left(\mathrm{CDCl}_{3}\right)$} & \multicolumn{3}{|c|}{$4\left(\mathrm{CDCl}_{3}\right)$} & \multicolumn{4}{|c|}{$5\left(\mathrm{C}_{6} \mathrm{D}_{6}\right)$} & \multicolumn{3}{|c|}{$6\left(\mathrm{C}_{6} \mathrm{D}_{6}\right)$} \\
\hline & ${ }^{13} \mathrm{C} \delta$ & ${ }^{1} \mathrm{H} \delta$ & ${ }^{13} \mathrm{C} \delta$ & ${ }^{1} \mathrm{H} \delta$ & $\begin{array}{l}\text { HMBC } \\
\text { (C No.) }\end{array}$ & ${ }^{13} \mathrm{C} \delta$ & ${ }^{1} \mathrm{H} \delta$ & $\mathrm{NOESY}^{\mathrm{c}}$ & $\begin{array}{l}\text { HMBC } \\
\text { (C No.) }\end{array}$ & ${ }^{13} \mathrm{C} \delta$ & ${ }^{1} \mathrm{H} \delta$ & NOESY $^{\mathrm{c}}$ \\
\hline 1 & 41.1 & $1.94 \mathrm{~m}$ & 41.3 & $1.96 m$ & $3 / 6,7,8,12$ & $\sim 127.6$ & - & - & - & 126.7 & - & - \\
\hline 2 & 27.9 & $\begin{array}{l}1.42 d d d d(6, \\
12,12,13) \\
1.70 \mathrm{~m}\end{array}$ & 27.7 & $\begin{array}{l}1.44 d d d d(6, \\
12,12,13) \\
1.72 \mathrm{~m}\end{array}$ & $\begin{array}{l}1,3 / 6,4 \\
1,3 / 6,4,7 ?\end{array}$ & 26.9 & $2.39, t(6)$ & 12 & $1,3,4,6 ?$ & 26.8 & $2.34 t(6)$ & 8 \\
\hline 3 & $30.7^{\mathrm{d}}$ & $\begin{array}{l}1.86 \mathrm{~m} \\
1.98 \mathrm{~m}\end{array}$ & 30.7 & $\begin{array}{l}1.89 \mathrm{~m} \\
2.05 \mathrm{~m}\end{array}$ & $1,2,4,5$ & 32.4 & $1.96, b r t(5)$ & & $2 ?, 4,5$ & 32.3 & 1.97 brt (5) & \\
\hline 4 & 133.7 & - & 133.7 & - & - & 134.0 & - & - & - & 133.9 & - & - \\
\hline 5 & 121.0 & $5.37 \mathrm{br} \mathrm{m}$ & 120.9 & $5.39 \mathrm{br} \mathrm{m}$ & 1,6 & 121.4 & $5.40 \mathrm{br} \mathrm{m}$ & & & 121.5 & $5.39 \mathrm{br} \mathrm{m}$ & \\
\hline 6 & $30.9^{\mathrm{d}}$ & $2 \mathrm{H}, 1.98 \mathrm{~m}$ & 30.7 & $2 \mathrm{H}, 1.96 \mathrm{~m}$ & $1,4,5$ & $29.8^{\prime}$ & $2.79, b r s$ & 8 & & $29.7^{\mathrm{d}}$ & $2.83 \mathrm{brs}$ & 12 \\
\hline 7 & 139.4 & - & 140.8 & - & - & 128.6 & - & - & - & 128.5 & - & - \\
\hline 8 & 130.1 & $5.09 \mathrm{~s}$ & 40.5 & $\begin{array}{l}1.705 s \\
1.709 s\end{array}$ & $\begin{array}{l}1 ?, 7,9 ?, 10 \\
, 12,13 / 14\end{array}$ & 43.8 & $1.97, s$ & $6,13 / 14$ & $\begin{array}{l}1,7,9,10 \\
13 / 14\end{array}$ & 43.5 & $2.01 s$ & $2,13 / 14$ \\
\hline 9 & 31.4 & - & 29.0 & - & - & $\sim 33.5$ & - & - & - & 33.3 & - & - \\
\hline 10 & 37.5 & $2 \mathrm{H}, 1.35 t(7)$ & 35.3 & $2 \mathrm{H}, 1.30 t(7)$ & $\begin{array}{l}8,9,11,12 \\
13,14\end{array}$ & 40.4 & $1.30, m$ & $13 / 14$ & $\begin{array}{l}8,9,11, \\
12 ?, 13 / 14\end{array}$ & 40.3 & $1.30 \mathrm{~m}$ & $13 / 14$ \\
\hline 11 & 20.2 & $2 \mathrm{H}, 1.58 \mathrm{~m}$ & 23.1 & $2 \mathrm{H}, 2.01 \mathrm{~m}$ & $7,9,10,12$ & 24.7 & $1.50 \mathrm{~m}$ & & $7,9,12$ & 24.3 & $1.46 \mathrm{~m}$ & \\
\hline 12 & 26.6 & $\begin{array}{l}1.846 t \\
1.850 t\end{array}$ & 117.8 & $5.36 \mathrm{br} \mathrm{m}$ & $1 / 8,10,11$ & $30.0^{\prime}$ & $2.15, b r t(6)$ & 2 & $\begin{array}{l}1,7,8,10 \\
11\end{array}$ & $30.4^{\mathrm{d}}$ & $2.09 \mathrm{brt}(6)$ & 6 \\
\hline 13 & $30.3^{\mathrm{e}}$ & $0.912 s$ & $28.0^{\mathrm{d}}$ & $0.890 s$ & $8,9 / 14,10$ & 28.6 & $0.88 s$ & 8,10 & $8,9,10,14$ & 28.7 & $0.89 s$ & 8,10 \\
\hline 14 & $30.4^{\mathrm{e}}$ & $0.915 s$ & $28.4^{\mathrm{d}}$ & $0.882 s$ & $8,9 / 13,10$ & 28.6 & $0.88 s$ & 8,10 & $8,9,10,13$ & 28.7 & $0.89 s$ & 8,10 \\
\hline 15 & 23.5 & $1.62 \mathrm{brs}$ & 23.5 & $1.64 \mathrm{brs}$ & $3,4,5$ & 23.6 & $1.63 \mathrm{br} \mathrm{m}$ & 3,5 & $3,4,5$ & 23.6 & $1.64 \mathrm{br} \mathrm{m}$ & 3,5 \\
\hline
\end{tabular}

\footnotetext{
${ }^{\mathrm{a}}{ }^{1} \mathrm{H}-{ }^{1} \mathrm{H}$ coupling constants $(\mathrm{Hz})$ in parentheses; query $(?)=$ weak or indistinct $2 \mathrm{D}$ signal; slash $(/)=$ and/or.

${ }^{\mathrm{b}}$ Solvent references, $\delta$ from TMS: $\mathrm{CDCl}_{3}{ }^{1} \mathrm{H} 7.26,{ }^{13} \mathrm{C} 77.0 ; \mathrm{C}_{6} \mathrm{D}_{6}{ }^{1} \mathrm{H} 7.15,{ }^{13} \mathrm{C} 128.0$

${ }^{\mathrm{c}}$ Two- and three-bond correlations not listed.

${ }^{\mathrm{d}, \mathrm{e}}$ Column entries with the same superscript may be reversed.
} 
from protons $2 \rightarrow 12$ and $6 \rightarrow 8$ in $\mathbf{5}$ vs from $2 \rightarrow 8$ and $6 \rightarrow 12$ in $\mathbf{6}$ (Table 1 ).

It should be noted that $\mathbf{5}$ and $\mathbf{6}$ were very unstable when purified, being oxidized and isomerised within minutes unless preserved with an antioxidant.

Minor component ar-macrocarpene $7\left(M_{r}=202\right)$ had ${ }^{1} \mathrm{H}$ NMR signals (see Experimental) that indicated its basic structural features: a bicyclic sesquiterpene consisting of a 1,4-disubstituted benzene ring $(4 \mathrm{H}, \delta 7.06)$ with a methyl group $(3 \mathrm{H}, \delta$ 2.18) and attached to a saturated cycloalkyl ring bearing a geminal methyl pair (two singlets, $\delta 0.91$ and $0.93,3 \mathrm{H}$ each). The macrocarpane structure suggested by these features was confirmed by GC comparison of the hydrogenation products of 7 with those of $\mathbf{4}$ and $\mathbf{6}$. All three starting materials produced the same two isomeric macrocarpanes, though in different ratios (see Experimental). Since 7 is chiral and was found to be dextrorotatory $\left(\alpha_{D}=+7.2^{\circ}\right)$, its enantiomeric purity was investigated by EGC. Neither 7 itself nor its hydrogenation products showed evidence of separable enantiomers. However, EGC analysis of the hydrogenation product mix from $\mathbf{6}$, which must contain both enantiomers of each diastereomer, also showed no separation of the enantiomeric pairs. Thus there is no assurance that 7 is optically pure. However, the fact that it is not racemic suggests that its biosynthesis involves a stereospecific enzymemediated hydride shift from C-1 to C-7 before aromatization. The absolute stereochemistry shown is based on the fact that 3,3-dimethylcyclohexanes with achiral $1 R$ substituents are reported to be dextrorotatory (Ansari, 1973). 
The structure of cyclobutanoid sesquiterpene $\mathbf{8}$, which is given the trivial name cumacrene, was determined by a series of 2D NMR experiments (data in Table 2). ${ }^{1} \mathrm{H}-$ ${ }^{1} \mathrm{H}$ TOCSY defined the coupled proton system H- $8 \rightarrow \mathrm{H}-9 \alpha \beta \rightarrow \mathrm{H}-10 \alpha \beta$, and HMQC gave the proton-carbon assignments. HMBC gave 2- and 3-bond heteronuclear correlations that were only consistent with a cyclobutane ring substituted as shown. The trans relative stereochemistry at C-7 and C-8 was clear from a strong NOESY peak between $\mathrm{H}-8$ and $\mathrm{H}-15$. The attachment of the 4-methylcyclohexene ring at $\mathrm{C}-1$ was required by the TOCSY and $\mathrm{HMBC}$ data.

The C-1/C-7 relative stereochemistry was investigated by comparing results of NOESY experiments (Table 2) with minimum-energy (MM2 force field) conformation calculations for $\mathbf{8}$ and its $\mathrm{C}-1$ diastereomer. The calculations for $\mathbf{8}$ found two low-

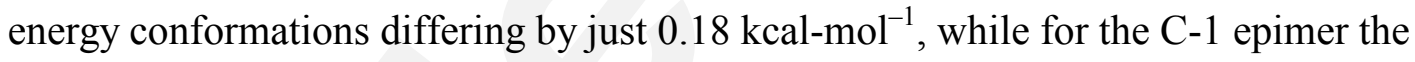
steric energy difference between the two lowest-energy conformations was $1 \mathrm{kcal}^{-\mathrm{mol}^{-1}}$. Potentially informative close contacts for $\mathbf{8}$ would be from quasi-equatorial $\mathrm{H}-6 \alpha$ to $\mathrm{H}-$ 13 in one conformation or to $\mathrm{H}-15$ in the other, while for the $\mathrm{C}-1$ epimer neither of these interactions would be expected. The NOESY experiment in $\mathrm{CDCl}_{3}$ was not definitive due to overlap of key signals, but in $\mathrm{C}_{6} \mathrm{D}_{6}$, where the broad $\mathrm{H}-6 \alpha$ multiplet as well resolved, there was a cross-peak indicating an H-13/H-6 $\alpha$ correlation. Furthermore, cross-peaks from H-15 to H- $6 \beta$ and $-6 \alpha$ appeared which suggested the participation of both conformations of $\mathbf{8}$ in the observed NOEs. 
Table 2

${ }^{13} \mathrm{C}$ NMR and ${ }^{1} \mathrm{H}$ data ${ }^{\mathrm{a}}$ of sesquiterpenes $\mathbf{8}$ and $\mathbf{1 2}, \delta$ from $\mathrm{TMS}^{\mathrm{b}}$

\begin{tabular}{|c|c|c|c|c|c|c|c|c|c|c|c|c|}
\hline \multirow[b]{2}{*}{$\begin{array}{c}\text { C } \\
\text { No. }\end{array}$} & \multicolumn{5}{|c|}{$\mathbf{8}\left(\mathrm{CDCl}_{3}\right)$} & \multicolumn{3}{|c|}{$8\left(\mathrm{C}_{6} \mathrm{D}_{6}\right)$} & \multicolumn{4}{|c|}{$12\left(\mathrm{CDCl}_{3}\right)$} \\
\hline & ${ }^{13} \mathrm{C} \delta$ & ${ }^{1} \mathrm{H} \delta$ & TOCSY $^{\mathrm{c}}$ & NOESY ${ }^{d}$ & $\begin{array}{l}\text { HMBC } \\
\text { (C No.) }\end{array}$ & ${ }^{13} \mathrm{C} \delta$ & ${ }^{1} \mathrm{H} \delta$ & NOESY $^{\mathrm{d}}$ & ${ }^{13} \mathrm{C} \delta$ & ${ }^{1} \mathrm{H} \delta$ & $\operatorname{cosy}^{\mathrm{e}}$ & $\mathrm{NOESY}^{\mathrm{d}, \mathrm{e}}$ \\
\hline 1 & 37.8 & $1.69 m$ & $2 \beta$ & $15 ?$ & $2,3,7,15$ & 38.2 & $1.79 \mathrm{~m}$ & $15 ?$ & 44.6 & - & - & - \\
\hline 2 & 24.3 & $\begin{array}{l}\beta 1.20 \mathrm{~m} \\
\alpha 1.73 \mathrm{~m}\end{array}$ & $\begin{array}{l}1,3 \alpha \beta \\
3 \alpha \beta ?\end{array}$ & 15 & $\begin{array}{l}1,3,6 \\
3,4\end{array}$ & 24.7 & $\begin{array}{l}\beta 1.20 \mathrm{~m} \\
\alpha 1.70 \mathrm{~m}\end{array}$ & 15 & 39.1 & $\begin{array}{l}e q 1.93 \mathrm{br} \mathrm{dm} \\
a x 2.01 \mathrm{brdm}\end{array}$ & $\begin{array}{l}3,14 \\
3,14\end{array}$ & 7 \\
\hline 3 & 31.3 & $\begin{array}{l}\beta 1.91 \mathrm{br} \mathrm{m} \\
\alpha 2.00 \mathrm{brm}\end{array}$ & $\begin{array}{l}2 \alpha ? \beta \\
2 \beta\end{array}$ & $\begin{array}{l}14 \\
14\end{array}$ & $\begin{array}{l}4 \\
4 ?\end{array}$ & 31.6 & $\begin{array}{l}1.86 \mathrm{br} \mathrm{dm} \\
1.98 \mathrm{br} \mathrm{m}\end{array}$ & $\begin{array}{l}14 \\
14\end{array}$ & 120.9 & $5.37 \mathrm{br} \mathrm{m}$ & $2 a x, e q ; 14$ & \\
\hline 4 & 133.7 & - & - & - & - & 133.3 & - & - & 133.9 & - & - & - \\
\hline 5 & 121.4 & $5.33 b r d(4)$ & $6 \alpha \beta$ & 14 & $1,3,6,14$ & 121.9 & $5.43 b r d(4)$ & 14 & 28.8 & $\begin{array}{l}a x 1.93 \mathrm{br} \mathrm{dm} \\
e q 2.01 \mathrm{brdm}\end{array}$ & $\begin{array}{l}6 \\
6\end{array}$ & 15 \\
\hline 6 & 26.5 & $\begin{array}{l}\beta 1.69 m \\
\alpha 1.93 m\end{array}$ & $\begin{array}{l}5 ? \\
5\end{array}$ & $\begin{array}{l}15 ? \\
15 ?\end{array}$ & & 27.0 & $\begin{array}{l}\beta 1.77 \mathrm{~m} \\
\alpha 2.05 \mathrm{br} \mathrm{dm}(14)\end{array}$ & $\begin{array}{l}15 \\
13,15\end{array}$ & 24.2 & $2 \mathrm{H}, 1.46 \mathrm{~m}$ & 5ax,eq & $12 Z, 13,15$ \\
\hline 7 & 46.2 & - & - & - & - & 46.4 & - & - & 58.0 & $2.18 m$ & $8 \alpha \beta$ & $2 a x, 13 ?$ \\
\hline 8 & 52.5 & $2.56 t(9)$ & $9 \alpha \beta$ & 13,15 & $\begin{array}{l}1,7,9,10,11 \\
12,13,15\end{array}$ & 52.8 & $2.48 t(8.9)$ & 13,15 & 27.9 & $\begin{array}{l}\beta 1.68 m \\
\alpha 1.79 m\end{array}$ & $\begin{array}{l}7,9 \alpha \beta \\
7,9 \alpha \beta\end{array}$ & $12 Z, 15 ?$ \\
\hline 9 & 19.9 & $\begin{array}{l}\beta 1.86 m \\
\alpha 1.94 m\end{array}$ & $\begin{array}{l}8,10 \beta \\
8,10 \beta\end{array}$ & $12 Z$ & $\begin{array}{l}7,8,10 \\
7,8,10,11\end{array}$ & 20.2 & $\begin{array}{l}\beta 1.83 \mathrm{~m} \\
\alpha 1.94 \mathrm{~m}\end{array}$ & $12 Z$ & 31.4 & $\begin{array}{l}\alpha 1.35 \mathrm{~m} \\
\beta 1.73 \mathrm{~m}\end{array}$ & $\begin{array}{l}8 \alpha \beta, 10 \\
8 \alpha \beta, 10\end{array}$ & 15 \\
\hline 10 & 29.6 & $\begin{array}{l}\beta 1.55 d t(9,11) \\
\alpha 1.79 m\end{array}$ & $9 \alpha \beta$ & 15 & $\begin{array}{l}1,7,8,9,15 \\
1,7,8,9\end{array}$ & 29.9 & $\begin{array}{l}\beta 1.46 d t(9,11) \\
\alpha 1.76 m\end{array}$ & 15 & 44.0 & $1.75 \mathrm{~m}$ & $9 \alpha, 15$ & \\
\hline 11 & 146.8 & - & - & - & - & 146.6 & - & - & 147.1 & - & - & - \\
\hline 12 & 110.0 & $\begin{array}{l}\text { (E) } 4.80 \mathrm{brs} \\
\text { (Z) } 4.71 \mathrm{brs}\end{array}$ & & $\begin{array}{l}13 \\
9 \alpha\end{array}$ & 8,13 & 110.5 & $\begin{array}{l}\text { (E) } 4.86 \mathrm{brs} \\
\text { (Z) } 4.82 \mathrm{brs}\end{array}$ & $\begin{array}{l}13 \\
9 \alpha\end{array}$ & 111.8 & $\begin{array}{l}\text { (Z) } 4.72 \mathrm{br} \mathrm{s} \\
\text { (E) } 4.83 \mathrm{br} \mathrm{m}\end{array}$ & $\begin{array}{l}7 ? \\
13\end{array}$ & $\begin{array}{l}6,8 \alpha, 15 \\
13\end{array}$ \\
\hline 13 & 23.8 & $1.77 \mathrm{brs}$ & & $8,12 E, 15$ & 8,12 & 23.9 & $1.70 \mathrm{brs}$ & $\begin{array}{l}6 \alpha, 8,12 E \\
15\end{array}$ & 24.1 & $1.77 \mathrm{~s}$ & & $6,7 ?, 12 E$ \\
\hline 14 & 23.4 & $1.63 \mathrm{brs}$ & & $3 \alpha \beta, 5$ & $3,4,5$ & 23.6 & $1.64 b r s$ & $3 \alpha \beta, 5$ & 23.3 & $1.61 \mathrm{brs}$ & $2 a x, e q$ & - \\
\hline 15 & 25.2 & $1.11 \mathrm{~s}$ & & $\begin{array}{l}1 ?, 2 \beta, 6 \alpha ? \beta ?, \\
8,10 \beta, 13\end{array}$ & $1,7,8,10$ & 25.4 & $1.03 \mathrm{~s}$ & $\begin{array}{l}1 ?, 2 \beta, 6 \alpha \beta \\
, 8,10 \beta, 13\end{array}$ & 15.8 & $0.94 d(7)$ & 10 & $\begin{array}{l}8 \alpha ?, 9 \alpha, 5 a x \\
6,12 Z\end{array}$ \\
\hline
\end{tabular}

\footnotetext{
${ }^{a} \mathrm{H}-{ }^{1} \mathrm{H}$ coupling constants $(\mathrm{Hz})$ in parentheses; query $(?)=$ weak or indistinct $2 \mathrm{D}$ signal.

${ }^{\mathrm{b}}$ Solvent references, $\delta$ from TMS: $\mathrm{CDCl}_{3}{ }^{1} \mathrm{H} 7.26,{ }^{13} \mathrm{C} 77.0 ; \mathrm{C}_{6} \mathrm{D}_{6}{ }^{1} \mathrm{H} 7.15,{ }^{13} \mathrm{C} 128.0$

${ }^{\mathrm{c}} 24 \mathrm{~ms}$ mixing time used to limit correlations to 2 and 3 bonds; two-bond correlations not listed.

${ }^{\mathrm{d}}$ Two- and three-bond correlations not listed.

${ }^{\mathrm{e}}$ Two-bond correlations not listed; assignments for $\mathrm{H}-2$ and -5 confirmed by COSY (or NOESY) experiment in $\mathrm{C}_{6} \mathrm{D}_{6}$.
} 
The depicted absolute stereochemistry of $\mathbf{8}$ is based on the assumption that the compound derives from the same $(S)$-bisabolyl precursor as congeners $\mathbf{3}$ and $\mathbf{4}$ (see discussion below).

A sesquiterpenoid carboxylic acid with the 1-(2-isopropyl-1-methyl-cyclobutyl)-4methylcyclohexane ("dunniane") carbon skeleton has been described from Illicium dunnianum (Sy and Brown, 1998). Besides the C-14 carboxyl functionality, this compound differs from $\mathbf{8}$ in having cis relative stereochemistry at C-7 and -8 . Thus the cumacrane and dunniane carbon skeletons bear the same stereochemical relationship as the cyclobutane monoterpenoids grandisol 9 and fragranol 10, respectively. In fact, cooccurrence of $\mathbf{8}$ with the macrocarpenes in C. macrocarpa suggests a biosynthetic parallel between sesquiterpene $\mathbf{8}$ and monoterpenoid $\mathbf{9}$, in that the latter also occurs naturally with corresponding monoterpenoid dimethylcyclohexane congeners, e.g. 2(3,3-dimethylcyclohexylidene)ethanol (Tumlinson et al., 1971).

Compound 11, another minor component ( $\sim 0.5 \%$ of total sesquiterpenes), had a MS quite similar to that of thujopsene. 1D NMR of the purified compound showed that it is a tricyclic sesquiterpene with four methyls (one of them vinyl) on quaternary carbons. Unlike thujopsene, there were no high-field signals indicative of a cyclopropane ring. The NMR data (in $\mathrm{C}_{6} \mathrm{D}_{6}$, see Experimental) were very similar to the literature values (in $\mathrm{CDCl}_{3}$ ) for one candidate structure, 2,2,6,8-tetramethyltricyclo[5.3.1.0 $\left.{ }^{1,6}\right]$ undec-8-ene (Naegeli and Wetli, 1981). A ${ }^{1} \mathrm{H}$ NMR experiment with the C. macrocarpa unknown in 
$\mathrm{CDCl}_{3}$ gave spectral data identical to the literature values, confirming its identification.

The compound reported by Naegeli and Wetli (1981) was a by-product in a synthesis of the 1,1,5,9-tetramethylspiro[5.5] undecane (chamigrane) skeleton. The authors note that acid-catalyzed scission of the $\mathrm{C}-1 / \mathrm{C}-10$ bond of 11 leads directly to the chamigrenes. This relationship and the presence of a pinene substructure prompt the proposal of $\alpha$ chamipinene as the trivial name for $\mathbf{1 1}$. None of the related compounds found by Naegeli and Wetli (which by analogy would be called $\beta$-chamipinene, chamicamphene, and $\alpha$-chamifenchene) was detected in C. macrocarpa.

Naegeli and Wetli (1981) synthesized racemic mixtures in their work, so there was no information on the optical rotation of the enantiomers of these compounds. But since the absolute stereochemistry of $\alpha$ - and $\beta$-chamigrene is known, it seemed possible to determine that of $\mathbf{1 1}\left(\alpha_{D}-4.3^{\circ}\right)$ by acid-catalyzed rearrangement followed by enantioselective analysis of any chamigrenes produced. When this was done, 11 completely rearranged to two major products that were identical to $(-)-\alpha-$ and $(-)-\beta$ chamigrene when analyzed by GC-MS and dual-column GC-FID, but differed in retention time from the $(-)$ enantiomers on EGC. Although $(+)-$ and $(-)-\alpha-$ chamigrene were only slightly separated, the $\beta$-chamigrene enantiomers were resolved to the baseline, showing that the enantiomeric purity of the $(+)-\beta$-chamigrene, and therefore of $\mathbf{1 1}$ itself, is very high. 
Acoradiene 12 is the $\mathrm{C}-10$ epimer of $(+)-\beta$-acoradiene. Its $\mathrm{GC}$ retention time was slightly longer than that of $\beta$-acoradiene, while its mass spectrum was very similar, the only significant difference being the somewhat larger ratio of ion $\mathrm{m} / \mathrm{z} 108$ to 107 . The structure and absolute stereochemistry of $\mathbf{1 2}$ were elucidated by a combination of 2D NMR, molecular mechanics (MM2) calculation, hydrogenation experiments, and EGC.

${ }^{1} \mathrm{H}-{ }^{1} \mathrm{H}$ COSY and ${ }^{1} \mathrm{H}-{ }^{13} \mathrm{C}$ HSQC experiments indicated the acoradiene structure and allowed assignment of the ${ }^{1} \mathrm{H}$ and ${ }^{13} \mathrm{C}$ signals (Table 2). Position of the endocyclic double bond at $\mathrm{C}-3^{1}$ was inferred from the $\delta 39 \mathrm{ppm}{ }^{13} \mathrm{C}$ signal for $\mathrm{C}-2$, which is significantly different from that of the corresponding allylic carbon of $\alpha$ - and $\beta$ acoradiene $(\delta \sim 31 \mathrm{ppm})$. This downfield chemical shift can be explained by absence of a $\gamma$ substituent interaction between Me-15 and C-2. Examination of the MM2 minimumenergy conformations of all four diastereomers of acora-3,11- and -4,11-diene shows that in three of them $\mathrm{H}-15$ is within $2.45 \AA$ of the nearest allylic proton $(\mathrm{H}-2$ or -6$)$. Only in $\mathbf{1 2}$ is this distance large enough (ca. $4.7 \AA$ ) to preclude the upfield shift typical for this allylic carbon.

GC-MS, dual-column GC-FID, and EGC comparison of the hydrogenation products of 12 and authentic (-)- $\alpha$-acoradiene $\mathbf{1 3}$ gave final proof of the relative and absolute stereochemistry at C-7 and C-10. Hydrogenation of $\mathbf{1 3}$ gave two major saturated $\left(M_{r}=\right.$

\footnotetext{
${ }^{1}$ In this discussion, numbering of the acoradienes begins at spiro C-1, with C-2 being the adjacent carbon in the cyclohexene ring that is trans to the isopropenyl group.
} 
208) compounds $\mathbf{1 4 a / b}$, along with small amounts of isopropyl epimers $14 \mathbf{c} / \mathbf{d}$.

Compound 12 gave nearly equal amounts of $\boldsymbol{e n t}-\mathbf{1 4 c} / \mathbf{d}$ and $\boldsymbol{e n t}-\mathbf{1 4 a} / \mathbf{b}$. The assumption that ent-14a/b were artefacts due to acid-catalysed isomerization at C-7 was tested by repeating the hydrogenation of $\mathbf{1 2}$ with addition of a small amount of pyridine. Though hydrogenation was less complete (there were now sizable amounts of monounsaturated $M_{r}=206$ compounds), the amount of ent $\mathbf{- 1 4 a / b}$ was greatly reduced compared to ent14c/d (see Experimental). An unexpected finding in this experiment was that although no unreacted 12 remained, a large peak corresponding to ent- $\gamma$-acoradiene [acora4,7(11)-diene] was seen.

A search through our in-house library of plant terpenoid GC-MS analyses showed that the mass spectrum of a sesquiterpene from the liverwort Pellia epiphylla (L.) Corda, collected in Humboldt Co., CA, very closely matched that of 12. GC-MS, dual-column GC-FID, and EGC comparisons under identical conditions showed that the P. epiphylla component, present at a concentration of ca. $2 \%$ in the oil, had MS and retention data exactly the same as that of $\mathbf{1 2}$ from C. macrocarpa. Thus the former is probably also (-)-10-epi- $\beta$-acoradiene.

A compound with the same structure as $\mathbf{1 2}$ (or its enantiomer) has been reported as an aggregation pheromone in the flour beetle Gnatocerus cornutus (Tebayashi et al., 1998). However, the published NMR and MS data are clearly different from those of $\mathbf{1 2 .}$ Since no conformational analysis was done, the authors' interpretation of the NOESY 
data for the beetle pheromone may be open to question. Of the four acora-3,11- and 4,11-diene diastereomers, only $\mathbf{1 2}$ and $\alpha$-acoradiene are consistent with the reported NOESY cross-peak from H-15 to non-allylic H-6 or -2 . But since the $\alpha$-acoradiene $\mathrm{NMR}$ data referred to in the paper was from a low-resolution experiment run in $\mathrm{CCl}_{4}$ rather than $\mathrm{CDCl}_{3}$, the possibility that the unknown (reported $\alpha_{\mathrm{D}}=+37.1^{\circ}$ ) might actually be the enantiomer of (-)- $\alpha$-acoradiene $\mathbf{1 3}$ was missed.

To check this, a high-resolution (400 MHz) ${ }^{1} \mathrm{H}$ NMR spectrum was run on authentic $\mathbf{1 3}$ in $\mathrm{CDCl}_{3}$. The resulting signals were identical to those reported by Tebayashi et al. (1998), with two exceptions: vinyl H-5 is at $\delta 5.30$, not 5.60 as reported; and vinyl Me14 is at $\delta 1.63$, not 1.67. Both of these discrepancies are doubtless due to typographical errors: the depicted COSY spectrum clearly shows Me-14 at $\delta 1.63$, and the authors characterize the ${ }^{1} \mathrm{H}$ signals of the Gnatocerus cornutus acoradiene as "similar to those in the literature" for $\alpha$ - and $\beta$-acoradiene, both of which have the vinyl methyl at $\delta 5.25$ $\left(\mathrm{CCl}_{4}\right.$ data). Thus the identity of the G. cornutus aggregation pheromone is revised to $(+)$ - $\alpha$-acoradiene.

A small amount of compound $\mathbf{1 5}$, with a widdrane carbon skeleton, was isolated and identified by 1D and 2D NMR experiments (Table 3). The essential features of the molecule were suggested by the 1D spectrum: a bicyclic sesquiterpene with three methyl singlets and a disubstituted double bond flanked by (a) methine proton $\mathrm{H}-1$ 
Table 3

${ }^{13} \mathrm{C}$ NMR and ${ }^{1} \mathrm{H}$ data ${ }^{\mathrm{a}}$ of sesquiterpenes $\mathbf{1 5}$ and $\mathbf{1 6}, \delta$ from TMS ${ }^{\mathrm{b}}$

\begin{tabular}{|c|c|c|c|c|c|c|c|c|c|c|}
\hline \multirow[b]{2}{*}{ C No. } & \multicolumn{5}{|c|}{$15\left(\mathrm{C}_{6} \mathrm{D}_{6}\right)$} & \multicolumn{5}{|c|}{$16\left(\mathrm{C}_{6} \mathrm{D}_{6}\right)$} \\
\hline & ${ }^{13} \mathrm{C} \delta$ & ${ }^{1} \mathrm{H} \delta$ & $\mathrm{TOCSY}^{\mathrm{c}}$ & NOESY $^{\mathrm{d}}$ & $\begin{array}{l}\text { HMBC } \\
\text { (C No.) }\end{array}$ & ${ }^{13} \mathrm{C} \delta$ & ${ }^{1} \mathrm{H} \delta$ & TOCSY $^{c}$ & NOESY $^{\mathrm{d}}$ & $\begin{array}{l}\text { HMBC } \\
\text { (C No.) }\end{array}$ \\
\hline 1 & 58.2 & $1.75 d(8)$ & 2 & $10 \beta, 13,15$ & $\begin{array}{l}2,6 / 7,8 ?, 11 \\
12,13,15\end{array}$ & 128.7 & - & - & - & - \\
\hline 2 & 131.1 & $5.55 d d(13,8)$ & 1,3 & 13 & $1 ?, 4,7 / 11$ & 26.9 & $2.34 \operatorname{brt}(6)$ & 3 & 8,9 & $1,3,4,6,7$ \\
\hline 3 & 132.6 & $6.28 b r d(13)$ & 2 & $14 Z$ & $1,5,14$ & 32.1 & $1.95 \mathrm{br} \mathrm{m}$ & 2 & 14 & $1,2,4,5,14 ?$ \\
\hline 4 & 148.0 & - & - & - & - & 133.9 & - & - & - & - \\
\hline 5 & 32.2 & $\begin{array}{l}\beta 2.48 \mathrm{tm}(14) \\
\alpha 2.30 \mathrm{ddd}(15,5,4)\end{array}$ & $\begin{array}{l}6 \alpha \beta \\
6 \alpha \beta\end{array}$ & $\begin{array}{l}15 \\
14 E\end{array}$ & $6 / 7$ & 121.3 & $5.39 \mathrm{brs}$ & 6 & 14 & \\
\hline 6 & 35.7 & $\begin{array}{l}\beta 1.08 \mathrm{~m} \\
\alpha 2.16 d d d(14,12,4)\end{array}$ & $\begin{array}{l}5 \alpha \beta \\
5 \alpha \beta\end{array}$ & $\begin{array}{l}15 ? \\
9 \alpha, 12\end{array}$ & $\begin{array}{l}1,7 ?, 8 ?, 5 / 15 \\
5 ?, 7,15\end{array}$ & 30.2 & $2.75 \mathrm{brs}$ & $5,14 ?$ & 15 & $1,4,5,7$ \\
\hline 7 & $\sim 36$ & - & - & - & - & 126.0 & - & - & - & - \\
\hline 8 & 44.6 & $\begin{array}{l}\beta 1.11 d d d(13,13,4) \\
\alpha 1.37 d d d(13,3,3)\end{array}$ & $\begin{array}{l}9 \alpha \beta \\
9 \alpha \beta\end{array}$ & $\begin{array}{l}15 ? \\
15\end{array}$ & $6 / 7,9 ?, 15$ & 33.9 & $2.07 \operatorname{brt}(8)$ & 9 & $2,10,15$ & $1,6,9,10,15$ \\
\hline 9 & 18.6 & $\begin{array}{l}\beta 1.29 \mathrm{~m} \\
\alpha 1.56 q t(14,3)\end{array}$ & $\begin{array}{l}8 \alpha / 10 \alpha, 8 \beta / 10 \beta \\
8 \alpha / 10 \alpha, 8 \beta / 10 \beta\end{array}$ & $6 \alpha, 12$ & $10 ?$ & 27.0 & $1.53 \mathrm{~m}$ & 8,10 & 2 & $7,8,10,11$ \\
\hline 10 & 42.0 & $\begin{array}{l}\beta 1.11 d d d(13,13,4) \\
\alpha 1.37 d d d(13,3,3)\end{array}$ & $\begin{array}{l}9 \alpha \beta \\
9 \alpha \beta\end{array}$ & $\begin{array}{l}1 \\
12\end{array}$ & $\begin{array}{l}8,9 ?, 12 ?, 13 ? \\
1,8 ?, 12,13 ?\end{array}$ & 38.0 & $1.97 \mathrm{br} \mathrm{m}$ & 9 & 8,12 & $8,9,11,12,13$ \\
\hline 11 & 36.7 & - & - & - & - & 145.8 & - & - & - & - \\
\hline 12 & 23.3 & $\alpha 0.93 s$ & & $6 \alpha, 9 \alpha, 10 \alpha$ & $1,10,11,13$ & 110.3 & $4.82 \mathrm{brs}$ & & 10,13 & $10,11,13$ \\
\hline 13 & 33.3 & $\beta 0.91 \mathrm{~s}$ & & 1,2 & $1,10,11,12$ & 22.5 & $1.66 \mathrm{brs}$ & & 12 & $10,11,12$ \\
\hline 14 & 114.2 & $\begin{array}{l}\text { (Z) } 4.83 \mathrm{br} \mathrm{s} \\
\text { (E) } 4.92 \mathrm{br} \mathrm{s}\end{array}$ & & $\begin{array}{l}3 \\
5 \alpha\end{array}$ & $\begin{array}{l}3,5 \\
3,5\end{array}$ & 23.6 & $1.63 \mathrm{brs}$ & $6 ?$ & 3,5 & $3,4,5$ \\
\hline 15 & 30.7 & $1.01 \mathrm{~s}$ & & $1,5 \beta, 6 \beta ?, 8 \alpha \beta ?$ & $1,6 / 7,8$ & 18.5 & $1.61 \mathrm{brs}$ & & 6,8 & $1,7,8$ \\
\hline
\end{tabular}

${ }^{\mathrm{a}}{ }^{1} \mathrm{H}-{ }^{1} \mathrm{H}$ coupling constants $(\mathrm{Hz})$ in parentheses; query (?) = weak or indistinct signal; slash $(/)=$ and/or.

${ }^{\mathrm{b}}$ Solvent references, $\delta$ from TMS: $\mathrm{CDCl}_{3}{ }^{1} \mathrm{H} 7.26,{ }^{13} \mathrm{C} 77.0 ; \mathrm{C}_{6} \mathrm{D}_{6}{ }^{1} \mathrm{H} 7.15,{ }^{13} \mathrm{C} 128.0$

${ }^{\mathrm{C}} 24 \mathrm{~ms}$ mixing time used to limit correlations to 2 and 3 bonds; two-bond correlations not listed.

${ }^{\mathrm{d}}$ Two- and three-bond correlations not listed. 
( $\delta 1.75$, doublet) at a bridgehead carbon; and (b) exo-methylene-bearing quaternary carbon C-4. A TOCSY experiment confirmed three correlated proton systems: the allylic protons at C-5 were coupled to $\mathrm{H}-6 \alpha, \beta$; three methylenes at $\mathrm{C}-8$, -9 , and -10 formed a second coupled system; and vinyl H-2 $(\delta 5.55, d d)$ was coupled to H-3 $(\delta 6.30$, d) and H-1. Since H-1 was coupled only to H-2, the other two carbon atoms adjacent to C-1 must be quaternary. HMQC accounted for 12 protonated carbons, so the three methyl singlets were obviously attached to these two quaternary carbons as a geminal pair and an angular methyl at the other bridgehead. The widdrane skeleton suggested by these data was confirmed by an HMBC experiment, which showed key correlations from $\mathrm{H}-12$ and -13 to $\mathrm{C}-1,-10$, and -11 ; $\mathrm{H}-6$ to $\mathrm{C}-15$; and $\mathrm{H}-15$ to $\mathrm{C}-1,-6 / 7$, and -8 . A cis ring fusion was evident from a ${ }^{1} \mathrm{H}-{ }^{1} \mathrm{H}$ NOESY experiment, which gave a clear crosspeak from $\mathrm{H}-15$ to H-1. The absolute stereochemistry was determined by EGC comparison of the two epimeric saturated hydrogenation products of $\mathbf{1 5}$ with those derived from authentic (+)-widdrol ( $7 S$ absolute stereochemistry). Generation of reference $(7 S)$-widdranes required a somewhat roundabout procedure, since dehydration of widdrol leads to the methyl migration product pseudowiddrene rather than widdradienes (Ito et al., 1974). (+)-Widdrol was first hydrogenated to dihydrowiddrol, which was found to be the desired cis-fused stereoisomer (see Experimental). This was then dehydrated to two monoenes, which mixture was in turn hydrogenated to produce the cis-widdrane epimers. These had retention times identical to those from $\mathbf{1 5}$ on dualcolumn capillary GC but different on EGC, which established the $7 R$ absolute stereochemistry of 15 . 
1D NMR of compound $\mathbf{1 6}$ showed it to be an achiral monocyclic sesquiterpene with three double bonds - one tetrasubstituted, one trisubstituted, and one disubstituted terminal methylene - and three vinyl methyl singlets. HMQC and HMBC experiments (Table 3) allowed all signals to be unambiguously assigned, proving the iso- $\gamma$ bisabolene structure. The $1 E$ geometry was determined by a ${ }^{1} \mathrm{H}-{ }^{1} \mathrm{H}$ NOESY experiment, which showed a cross peak from H-15 to bis-allylic H-6. Though it is a new natural product, this compound has been synthesized in a 60:40 mixture with the $1 Z$ isomer, and the reported NMR data (in $\mathrm{CDCl}_{3}$ ) and MS data are very close to that found for $\mathbf{1 6}$ (Braun et al., 2003).

Production of very complex mixtures of constitutive sesquiterpenes by a single enzyme catalyst has been demonstrated in Abies grandis stem tissue (Steele et al, 1998). It is proposed that biosynthesis of the novel sesquiterpenes in C. macrocarpa foliage likewise involves a single "macrocarpene synthase" and can be rationalized as in Scheme 1. The first step (not shown) is cyclase-catalyzed isomerization of $(E, E)$ farnesyl diphosphate to (3S)-nerolidyl diphosphate (NPP) in the preferred anti-endo conformation (Cane, 1985, 1999). Ionization and C-1, C- $6^{1}$ closure then generates an (S)-bisabolyl carbocation that is the proposed precursor of all product sesquiterpenes.

Macrocarpenes 3-7 can be considered to arise via path (a), the first step of which is

\footnotetext{
${ }^{1}$ NPP numbering is used throughout this discussion.
} 


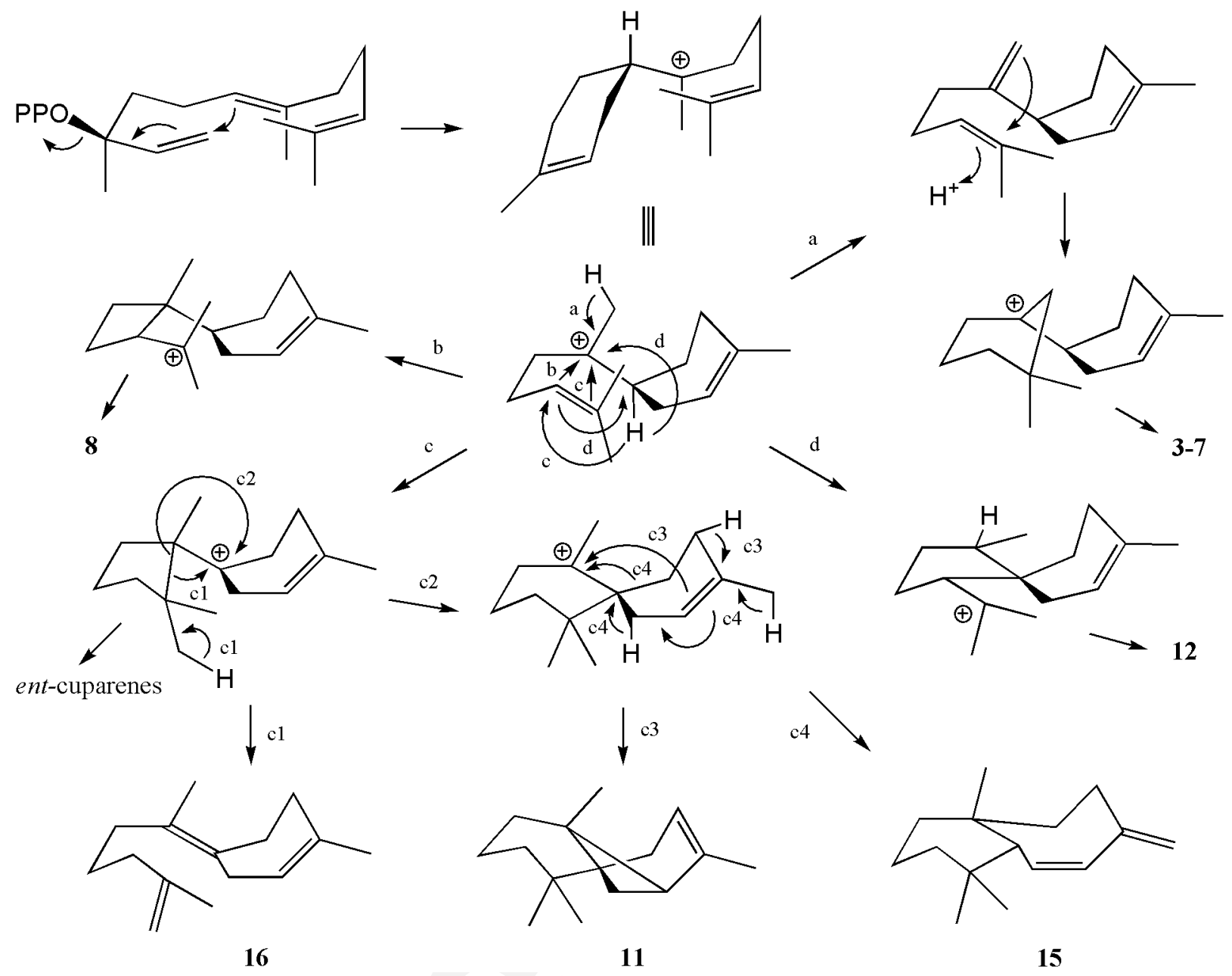

Scheme 1. Proposed mechanism for biosynthesis of novel C. macrocarpa sesquiterpenes via an $(S)$ bisabolyl carbocation.

deprotonation of the bisabolyl carbocation to (S)- $\beta$-bisabolene. This neutral intermediate is not released from the enzyme active site but is immediately reprotonated at $\mathrm{C}-10$ with ring closure from the $\mathrm{C}-7$ methylene to $\mathrm{C}-11$. (A similar mechanism has been adduced by Erman (1985) in the biogenesis of the dimethylcyclohexylidene monoterpenoid pheromones in Anthonomus grandis.) Deprotonation of the resulting macrocarpene carbocation at $\mathrm{C}-6, \mathrm{C}-8$, or at the newly incorporated methylene $(\mathrm{C}-12$ in 
macrocarpene numbering) gives 3-6, while a C-6, C-7 hydride shift followed by aromatization accounts for ar-macrocarpene 7.

Path (b), involving C-7, C-10 cyclization of the original (S)-bisabolyl carbocation with proton loss from C-12, leads to 8 . Alternatively, path (c), C-7, C-11 cyclization with a well-attested C-6, C-10 hydride shift (Cane, 1981, and references therein; Nabeta et al., 1993), generates an ent-cuparenyl carbocation. Deprotonation of this cation accounts for the rare (7S)-cuparenes observed, while C-7, C-11 bond scission with deprotonation at C-12 [path (c1)] is a plausible mechanism leading to bisabolene 16, with its unusual C-12 unsaturation.

An alternative reaction of the ent-cuparenyl carbocation is C-7, C-6 skeletal rearrangement (c2), which generates an ent-chamigrenyl carbocation. This opens the way to 11 via path (c3), C-2, C-7 closure with C-4 deprotonation; and to 15 by path (c4), C-6, C-7 skeletal rearrangement and a C-1, C-6 hydride and double bond shift, with deprotonation at the C-3 methyl.

Finally, biosynthesis of acoradiene $\mathbf{1 2}$ [route (d)] requires a 1,2 hydride shift from C-6 to C-7 of the bisabolyl carbocation (Nabeta et al., 1990) followed by C-6, C10 cyclization and proton loss from C-12. 


\section{Experimental}

\section{General experimental procedures}

Survey analyses of C. macrocarpa trees were done by grinding ca. $2 \mathrm{~g}$ of $\mathrm{LN}_{2}$-frozen foliage from each tree, extracting overnight with $n$-pentane, and analyzing the extracts by GC-MS (SE-54 WCOT column) and dual-column GC-FID (SE-54 and OV-17

WCOT columns) under these conditions: splitless $(0.7 \mathrm{~min})$ injection, injector $220^{\circ} \mathrm{C}$, FID detector $250{ }^{\circ} \mathrm{C}$, column(s) $35^{\circ} \mathrm{C}(0.7 \mathrm{~min}), 6{ }^{\circ} \mathrm{C}-\mathrm{min}^{-1}$ program to $250{ }^{\circ} \mathrm{C}$. The same GC conditions were used for retention time determinations of purified sesquiterpenes.

Hydrodistillation of bulk samples of $\mathrm{LN}_{2}$-ground foliage was from satd $\mathrm{NaCl}$ with $\mathrm{NaHCO}_{3}$ as previously described (Kim et al., 1994).

LC of hydrodistilled oil (silica gel; hexane-EtOAc eluents) and FTIR of purified compounds were described before (Kim et al., 1994), as was EGC on a 10\% permethyl$\beta$-cyclodextrin column (Cool, 2001).

\section{Plant material}

Small survey samples of foliage were taken from 20 widely-separated trees in the Point Lobos population of Cupressus macrocarpa in March 1996. Planted specimens (20 
trees) were similarly sampled from the University of California Richmond Field Station in July 2001, and the horticultural tree with the highest yield of macrocarpenes was used for compound isolation.

\section{Sesquiterpene isolation and identification}

The $n$-pentane extract (ca. $2 \mathrm{ml}$ ) of foliage from a tree containing germacrene $\mathrm{C}$ and the guaiadienes was concentrated 10 -fold under $\mathrm{N}_{2}$. This was applied to a column of silica gel in a Pasteur pipette and the hydrocarbon fraction eluted with 2 column volumes of $n$ hexane. (+)-Guaia-6,9-diene 1 was identified by GC-MS, dual-column GC-FID, and EGC comparison of the hydrocarbon fraction with authentic (-)-guaia-6,9-diene from commercial rose geranium (Pelargonium graveolens) oil. The MS of the standard and the C. macrocarpa component were identical, as were the $\mathrm{GC}$ retention times under all conditions except on EGC.

Guaia-6,10(15)-diene 2 was tentatively identified by the similarity of its MS with that of the compound from Nephthea chabrolii (K. Venkateswarlu, personal communication). GC-MS 70 eV, m/z (rel.int.): $204[\mathrm{M}]^{+}$(57), 189 [M-Me $]^{+}$(31), 161 (100), 147 (20), 133 (48), 119 (61), 105 (87), 91 (92), 81 (55), 67 (38), 55 (37), 41 (59).

For isolation of the remaining sesquiterpenes, ca. $4000 \mathrm{~g}$ of $\mathrm{LN}_{2}$-ground foliage from the chosen horticultural tree was hydrodistilled in $800 \mathrm{~g}$ batches, yielding ca. $20 \mathrm{~g}$ oil. Additional oil was obtained by $9 \times$ batchwise hexane extraction of -20 mesh ground air- 
dried foliage (1700 g), extract solvent removal, and subsequent hydrodistillation of the dark green residue $(89 \mathrm{~g})$ with $400 \mathrm{ml}$ satd $\mathrm{NaCl}$ and $10 \mathrm{~g} \mathrm{NaHCO}$, yielding another 20 $\mathrm{g}$ of oil. The combined oils ( $40 \mathrm{~g}$ ) consisted of ca. $86 \%$ monoterpenoids, $9 \%$ sesquiterpenoids, and 5\% diterpenoids. Before silica gel LC, most of the monoterpenes were removed by evaporation under $\mathrm{N}_{2}$ flow at ca. $120^{\circ} \mathrm{C}$, giving $13 \mathrm{~g}$ of monoterpenedepleted oil.

The first LC fraction, eluted with $n$-hexane, consisted solely of hydrocarbons. This fraction $(8 \mathrm{~g})$ was separated by repeated complexation LC of $1.5 \mathrm{~g}$ portions on $50 \mathrm{~g}$ of $20 \% \mathrm{AgNO}_{3} /$ silica gel using hexane-toluene step gradients, giving 11 fractions. Minor fractions 1-3, 8 and 10 (each $<0.1 \mathrm{~g}$, complex mixtures of trace compounds) and major fraction 5 (1.6 g, mostly 3 ), were not further analyzed. Part of major fraction $6(3 \mathrm{~g})$, consisting mainly of $\mathbf{3}$ and $\mathbf{4}$, was subjected to prep. GC (see below) to give analytical samples (ca. $20 \mathrm{mg}$ each) of $\mathbf{3}$ and 4. Fraction 4 (0.6 g), consisting of ca. 100:3:1:1 3, 11, 7 and 15 was re-chromatographed with $1 \%$ toluene/hexane to give a sub-fraction (ca. $0.1 \mathrm{~g}$ ) enriched in 7, 11 and 15 . In the case of 5-8, 11, 12 and 15, further separation was by isocratic HPLC (hexane-toluene eluents; RI detection) of portions of fractions rich in these compounds on a $10 \times 250 \mathrm{~mm}$ column packed with $15 \% \mathrm{AgNO}_{3} /$ silica gel $(5 \mu)$, using the following toluene concentrations: $1.8 \%$ for fraction 4 sub-fraction $(7,11$ and $\mathbf{1 5}), 3.5 \%$ for fraction $7(1.3 \mathrm{~g})(\mathbf{5}$ and $\mathbf{6}), 7 \%$ for fraction $9(0.2 \mathrm{~g})(\mathbf{8}$ and $\mathbf{1 2})$. Final purification of all except 16 was by prep. GC on $4 \mathrm{~mm}$ i.d. packed columns (OV-17 column, $170{ }^{\circ} \mathrm{C}$ for $\mathbf{3 , 4 , 8}$ and 12 ; SE-30 column, $185^{\circ} \mathrm{C}$ for 7,11 and 15 ; Carbowax 
$20 \mathrm{M}$ column, $165^{\circ} \mathrm{C}$ for $\mathbf{5}$ and $\mathbf{6}$ ). Compounds $\mathbf{5}$ and $\mathbf{6}$ were very prone to rearrangement and oxidation. Therefore, they were collected in capped $3 \mathrm{~mm}$ OD glass U-tubes which were treated with a solution of $100 \mu \mathrm{g}$ each of antioxidant (Ionox 330, Ethyl Corp.) and pyridine- $d_{5}$ in $5 \mu$ of pentane, applied in the condensation zone of the U-tubes just before use. $\beta$-Sesquiphellandrene and 16, in argentation LC fraction 11 (0.9 g; predominantly diterpenes), were inseparable by $\mathrm{GC}$ or $\mathrm{AgNO}_{3} /$ silica gel HPLC, but normal-phase silica gel HPLC ( $5 \mu$ particle size; $10 \times 250 \mathrm{~mm}$ column; RI detection) with $n$-hexane eluent partially resolved them, yielding $>97 \%$ pure samples of 16 (12 $\mathrm{mg}$ ) and $\beta$-sesquiphellandrene $\left(9 \mathrm{mg} ;[\alpha]_{\mathrm{D}}^{22} \approx-15^{\circ}, \mathrm{c} 5 ; \mathrm{CDCl}_{3}\right)$.

Chirality of (-)-cuparene and (-)- $\alpha$-cuprenene was determined by EGC comparison of prep. GC or HPLC fractions rich in the appropriate compound with cedarwood (Juniperus sp.) oil hydrocarbon fractions enriched in $(+)$ enantiomers of these compounds.

Hydrogenation experiments on 4, 6, and 7 were done under 70 atm $\mathrm{H}_{2}$ with ca. $2 \mathrm{mg}$ sesquiterpene and catalytic amounts of $\mathrm{PtO}_{2}$ in $200 \mu$ hexane. The same two $M_{r}=208$ products, inseparable on a 5\% phenyl methylpolysiloxane WCOT column but separable on $50 \%$ phenyl methylpolysiloxane, were produced from each starting material, in the

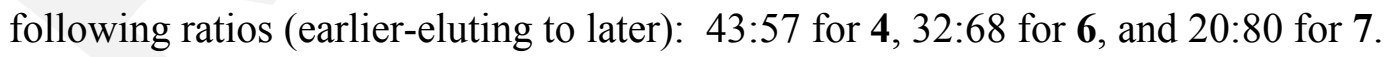

All IUPAC names were obtained using the ACD/I-Lab Web service (ACD/IUPAC 
Name Free 7.06).

(-)- $\alpha$-Macrocarpene, (1'S)-3,3,4'-trimethyl-1,1'-bi(cyclohexane)-1,3'-diene (3)

Oil. $[\alpha]_{\mathrm{D}}^{22}-81^{\circ}\left(c 3.9 ; n\right.$-hexane); IR $v \underset{\max .}{\mathrm{KBr}} \mathrm{cm}^{-1}: 2930,1453,1377,1358,1207$, 1147, 1035, 939, 914, 858, 789; HREIMS: $m / z$ found 204.1883, calc. for $\mathrm{C}_{15} \mathrm{H}_{24}$ 204.1878; GC-MS 70 eV, m/z (rel.int.): 204 [M] (16), 189 (19), 176 (4), 162 (3), 148 (6), 136 (64), 121 (100), 107 (26), 95 (86), 93 (53), 92 (33), 79 (27), 67 (18), 55 (20), 41 (28).

(-)- $\beta$-Macrocarpene, (1'S)-4',5,5-trimethyl-1,1'-bi(cyclohexane)-1,3'-diene (4)

Oil. $[\alpha]_{\mathrm{D}}^{22}-72^{\circ}\left(c 2.2 ; n\right.$-hexane); IR $v_{\max .}^{\mathrm{KBr}} \mathrm{cm}^{-1}: 2911,1471,1363.1217,1146,948$, 914, 833, 796; HREIMS: $m / z$ found 204.1883, calc. for $\mathrm{C}_{15} \mathrm{H}_{24}$ 204.1878; GC-MS 70 eV, $m / z$ (rel.int.): $204[\mathrm{M}]^{+}$(33), 189 (22), 175 (7), 162 (6), 148 (13), $136(53), 121$ (56), 107 (53), 105 (18), 95 (20), 94 (33), 93 (100), 92 (40), 91 (23), 80 (41), 79 (50), 67 (17), 55 (19), 41 (38).

(Z)- $\gamma$-Macrocarpene, (1Z)-3',3',4-trimethyl-1,1'-bi(cyclohexane)-1(1'),3-diene (5) Oil. HREIMS: $m / z$ found 204.1883, calc. for $\mathrm{C}_{15} \mathrm{H}_{24}$ 204.1878; GC-MS $70 \mathrm{eV}, \mathrm{m} / \mathrm{z}$ (rel.int.): $204[\mathrm{M}]^{+}(59), 189$ (10), 161 (19), 135 (25), 133 (18), 121 (20), 119 (26), 107 (36), 105 (43), 95 (27), 94 (100), 93 (79), 92 (28), 91 (50), 81 (19), 79 (57), 69 (31), 55 (31), $41(53)$. 
(E)- 8-Macrocarpene, (1E)-3',3',4-trimethyl-1,1'-bi(cyclohexane)-1(1'),3-diene (6)

Oil. HREIMS: $m / z$ found 204.1883, calc. for $\mathrm{C}_{15} \mathrm{H}_{24}$ 204.1878; GC-MS $70 \mathrm{eV}, \mathrm{m} / z$ (rel.int.): $204[\mathrm{M}]^{+}$(59), 189 (10), 161 (13), 135 (26), 133 (22), 121 (30), 119 (35), 107 (38), 105 (43), 95 (30), 94 (100), 93 (86), 92 (30), 91 (51), 81 (19), 79 (58), 69 (29), 55 (35), 41 (51); ${ }^{1} \mathrm{H}$ NMR (400.13 MHz, $\mathrm{CDCl}_{3}$,solvent ref. $7.26, \delta$ from TMS): $0.86(6 \mathrm{H}$, $s, \mathrm{H}-13,-14), 1.34$ (2H, $m, \mathrm{H}-10), 1.48$ (2H, m, H-11), $1.66(3 \mathrm{H}, b r s, \mathrm{H}-15), 1.98(2 \mathrm{H}$, $b r t, \mathrm{H}-3), 1.99(2 \mathrm{H}, s, \mathrm{H}-8), 2.10(2 \mathrm{H}, b r t, J=6.1 \mathrm{~Hz}, \mathrm{H}-12), 2.33(2 \mathrm{H}, t, J=6.3 \mathrm{~Hz}$, H-2), $2.80(2 \mathrm{H}, b r s, \mathrm{H}-6), 5.37(1 \mathrm{H}, b r m, \mathrm{H}-5) ;{ }^{13} \mathrm{C} \mathrm{NMR} \mathrm{(100.6} \mathrm{MHz,} \mathrm{CDCl} 3$, solv. ref. 77.0, $\delta$ from TMS): 23.4 ( $q, \mathrm{C}-15), 23.9(t, \mathrm{C}-11), 26.3(t, \mathrm{C}-2), 28.5$ (2C, $q, \mathrm{C}-13,-$ 14), 29.2 ( $t, \mathrm{C}-3), 30.1(t, \mathrm{C}-12), 31.9$ ( $t, \mathrm{C}-6), 33.2(s, \mathrm{C}-9), 40.1(t, \mathrm{C}-10), 43.2(t, \mathrm{C}-8)$, $121.0(d, \mathrm{C}-5), 126.2$ ( $s, \mathrm{C}-1), 128.6(s, \mathrm{C}-7), 134.2(s, \mathrm{C}-4)$; multiplicities by DEPT.

(+)-Ar-macrocarpene, 1-[(1R)-3,3-dimethylcyclohexyl]-4-methylbenzene (7)

Oil. $[\alpha]_{D}^{22}+7.2^{\circ}$ (c 5.1; $n$-hexane); HREIMS: $m / z$ found 202.1728, calc. for $\mathrm{C}_{15} \mathrm{H}_{22}$ 202.1722; GC-MS 70 eV, m/z (\% rel.int.): $202[\mathrm{M}]^{+}$(93), 187 (11), 159 (53), 131 (49), 118 (39), 117 (23), 105 (100), 91 (19), 57 (14), 41 (14). ${ }^{1} \mathrm{H}$ NMR (400.13 MHz, $\mathrm{C}_{6} \mathrm{D}_{6}$, solvent ref. 7.15, $\delta$ from TMS): $0.91(3 \mathrm{H}, s), 0.93(3 \mathrm{H}, s), 1.09(1 \mathrm{H}, d d d, J=4.5,13.1$, $13.1 \mathrm{~Hz}), 1.23(1 \mathrm{H}, d d d d, J=4.5,12.6,12.6,12.6 \mathrm{~Hz}), 1.26(1 \mathrm{H}, d d, J=12.8,12.8 \mathrm{~Hz})$, $1.33(1 \mathrm{H}, b r d, J=12.9 \mathrm{~Hz}), 1.46(1 \mathrm{H}, d d d d d, J=3.5,3.5,13.2,13.2,13.2 \mathrm{~Hz}), 1.49-$ $1.58(2 \mathrm{H}, m), 1.83(1 \mathrm{H}, b r d, J=12.8 \mathrm{~Hz}), 2.18(3 \mathrm{H}, s), 2.62(1 \mathrm{H}, d d d d, J=3.4,3.4$, 12.7, $12.7 \mathrm{~Hz}), 7.06(4 \mathrm{H}, s) ;{ }^{13} \mathrm{C} \mathrm{NMR}\left(100.6 \mathrm{MHz}, \mathrm{C}_{6} \mathrm{D}_{6}\right.$, solvent ref. $128.0, \delta$ from 
TMS): $21.0(q), 23.1(t), 24.7(q), 31.3(s), 33.6(q), 34.6(t), 39.2(t), 39.9(d), 48.0(t)$, $127.2(2 \mathrm{C}, d), 129.3(2 \mathrm{C}, d), 135.2(s), 145.0(s)$; multiplicities by DEPT.

(-)-Cumacrene, (4S)-4-[(1R,2S)-2-isopropenyl-1-methylcyclobutyl]-1methylcyclohexene (8)

Oil. $[\alpha]_{\mathrm{D}}^{22}-77^{\circ}\left(c 1.7 ; n\right.$-hexane); HREIMS: $m / z$ found 204.1877 , calc. for $\mathrm{C}_{15} \mathrm{H}_{24}$ 204.1878; GC-MS 70 eV, $m / z$ (\% rel.int.): 204 [M] ${ }^{+}$(2), 189 (3), 175 (17), 161 (9), 147 (4), 136 (8), 121 (49), 109 (23), 107 (38), 105 (14), 94 (43), 93 (100), 79 (31), 68 (84), 67 (41), 55 (17), 53, (21), 41 (32).

(-)- $\alpha$-Chamipinene, (1S,6S, 7S)-2,2,6,8-tetramethyltricyclo[5.3.1.0 $\left.{ }^{1,6}\right]$ undec-8-ene (11) Oil. $[\alpha]_{\mathrm{D}}^{22}-4.3^{\circ}\left(c 4.4, n\right.$-hexane); HREIMS: $m / z$ found 204.1877 , calc. for $\mathrm{C}_{15} \mathrm{H}_{24}$ 204.1878; GC-MS 70 eV, m/z (rel.int.): 204 [M] $]^{+}$(6), 189 (2), 161 (2), 147 (3), 133 (22), 123 (17), 121 (16), 119 (100), 111 (36), 105 (33), 94 (27), 93 (40), 92 (30), 91 (25), 81 (13), 69 (44), 55 (27), 41 (28); ${ }^{1} \mathrm{H}$ NMR (400.13 MHz, $\mathrm{C}_{6} \mathrm{D}_{6}$, solvent ref. 7.15, $\delta$ from TMS): $0.69(3 \mathrm{H}, s), 0.79(3 \mathrm{H}, s), 0.89(3 \mathrm{H}, s), 1.16(1 \mathrm{H}, d, J=8.4 \mathrm{~Hz}), 1.18$ $(1 \mathrm{H}, d m, J \approx 12 \mathrm{~Hz}), 1.67(3 \mathrm{H}, m), 1.74(1 \mathrm{H}, d d, J=5.7,1.6 \mathrm{~Hz}), 1.98(1 \mathrm{H}, d m, J=$ $17.2 \mathrm{~Hz}), 2.07(1 \mathrm{H}, d m, J=17.0 \mathrm{~Hz}), 2.24(1 \mathrm{H}, d d, J=8.3,5.7 \mathrm{~Hz}), 5.29(1 \mathrm{H}, b r m, J=$ 1.6 Hz); ${ }^{13} \mathrm{C}$ NMR (100.6 MHz, $\mathrm{C}_{6} \mathrm{D}_{6}$, solvent ref. $128.0, \delta$ from TMS): $18.2(t), 18.7$ $(q), 21.9(q), 22.5(q), 24.0(q), 30.8(t), 31.4(s), 31.5(t), 34.8(t), 38.1(t), 38.2(s), 44.4$ $(. d), 47.2(s), 117.0(d), 142.0(s)$; multiplicities by DEPT. 
Acid-catalyzed rearrangement of (-)- $\alpha$-chamipinene- $3 \mathrm{mg} 11$ and $1 \mathrm{mg}$ $\mathrm{Cu}(\mathrm{OAc})_{2} \cdot \mathrm{H}_{2} \mathrm{O}$ were dissolved in $100 \mu \mathrm{l}$ of HOAc in a $1 \mathrm{ml}$ vial, which was briefly flushed with argon then capped. After $18 \mathrm{hr}$ in a $110^{\circ}$ oven, the vial was cooled and the contents diluted $20 \times$ with water and shaken $3 \times$ with $1 \mathrm{ml}$ pentane. The combined pentane extracts were washed with dil. aq $\mathrm{NaHCO}_{3}$, dried over $\mathrm{Na}_{2} \mathrm{SO}_{4}$, and analyzed by GC (2 columns), GC-MS, and EGC. Major products were (+)- $\alpha$-chamigrene (44\%) and (+)- $\beta$-chamigrene (38\%), identical by GC and GC-MS (but differing in r.t. on EGC) with (-)- $\alpha$ - and (-)- $\beta$-chamigrene produced by acid-catalyzed rearrangement of authentic (-)-thujopsene under the same conditions (Daeniker et al., 1972).

(-)-10-epi- $\beta$-Acoradiene, (1S,4S, 5R)-1-isopropenyl-4,8-dimethyl-spiro[4.5]dec-7-ene (12)

Oil. $[\alpha]_{\mathrm{D}}^{22}-4.1^{\circ}\left(c 1.8, n\right.$-hexane); HREIMS: $m / z$ found 204.1877 , calc. for $\mathrm{C}_{15} \mathrm{H}_{24}$ 204.1878; GC-MS 70eV, m/z (rel.int.): 204 [M] ${ }^{+}$(7), 189 (5), 175 (2), 161 (16), 148 (10), 147 (21), 134 (8), 133 (12), 121 (52), 119 (100), 108 (21), 107 (23), 105 (40), 93 (62), 91 (27), 79 (30), 68 (16), 67 (17), 55 (18), 53 (12), 41 (28); ${ }^{1} \mathrm{H}$ NMR (500.17 $\mathrm{MHz}, \mathrm{C}_{6} \mathrm{D}_{6}$, solvent ref. 7.15, $\delta$ from TMS): $0.93(3 \mathrm{H}, d, J=6.7 \mathrm{~Hz}, \mathrm{H}-15), 1.29(1 \mathrm{H}$, $m, \mathrm{H}-9 \alpha), 1.44(2 \mathrm{H}, d d, J=6.8,6.0 \mathrm{~Hz}, \mathrm{H}-6), 1.62(3 \mathrm{H}, b r s, \mathrm{H}-14), 1.64(1 \mathrm{H}, m, \mathrm{H}-$

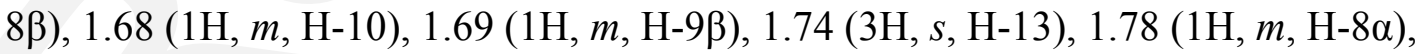
$1.88(2 \mathrm{H}, b r d m, J \approx 17 \mathrm{~Hz}, \mathrm{H}-2 e q, \mathrm{H}-5 a x), 2.00(2 \mathrm{H}, b r d m, J \approx 17 \mathrm{~Hz}, \mathrm{H}-2 a x, \mathrm{H}-$ 5eq), $2.14(1 \mathrm{H}, d d, J=9.8,8.3 \mathrm{~Hz}, \mathrm{H}-7), 4.80(1 \mathrm{H}, s,(Z)-\mathrm{H}-12), 4.90$ (1H, $s,(E)-\mathrm{H}-12)$, $5.38(1 \mathrm{H}, b r s, \mathrm{H}-5) ;{ }^{13} \mathrm{C} \mathrm{NMR}\left(125.8 \mathrm{MHz}, \mathrm{C}_{6} \mathrm{D}_{6}\right.$, approx. $\delta$ from TMS, protonated 
carbons, indirect detection; multiplicities by HMQC): 15.8 (q, C-15), 23.3 ( q, C-14), $24.0(q, \mathrm{C}-13), 24.0(t, \mathrm{C}-2), 27.8(t, \mathrm{C}-9), 28.9(t, \mathrm{C}-3), 31.5(t, \mathrm{C}-9), 39.1(t, \mathrm{C}-6), 44.1$ (d, C-10), $58.1(d, \mathrm{C}-7), 112.2(t, \mathrm{C}-12), 121.2(d, \mathrm{C}-5)$.

Hydrogenation of 12 and (-)- $\alpha$-acoradiene $13-$ ca. $1 \mathrm{mg}$ of sesquiterpene in ca. $300 \mu \mathrm{l}$

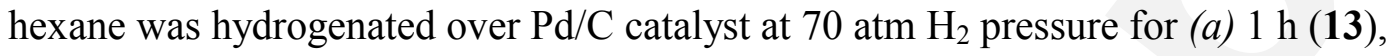
giving $M_{r} 208$ products 14a-d in ratios 23:69:2:6; (b) $12 \mathrm{~h}$ (12), giving $M_{r} 208$ products ent-14a-d in ratios 8:43:6:43; (c) 2 h (12 with a trace of pyridine), giving $M_{r} 208$ products ent-14a-d in ratios 1:9:19:71.

(-)-Widdra-2,4(14)-diene, (4aR,9aR)-1,1,4a-trimethyl-7-methylene-2,3,4,4a,5, 6, 7,9aoctahydro-1H-benzo[7] annulene (15)

Oil. $[\alpha]_{\mathrm{D}}^{22} \approx-18^{\circ}\left(c 0.27\right.$, benzene- $\left.d_{6}\right) ; \mathrm{UV} \lambda_{\max }^{\text {hexane }} \mathrm{nm}(\log \varepsilon): 233$ (3.8); GC-MS 70 eV, $m / z$ (rel.int.): $204[\mathrm{M}]^{+}$(18), 189 (39), 161 (49), 148 (23), 133 (47), 123 (37), 121 (54), 119 (61), 111 (78), 105 (100), 94 (80), 93 (78), 91 (95), 79 (63), 69 (58), 55 (42), 41 (72).

Hydrogenation of (+)-widdrol and 15; determination of absolute stereochemistry: 30 mg authentic (+)-widdrol ( $7 \mathrm{~S}$ absolute stereochemistry), dissolved in $0.4 \mathrm{ml} \mathrm{AcOH}$ and with a catalytic amount of $\mathrm{PtO}_{2}$, was hydrogenated for $18 \mathrm{hr}$ by bubbling in $\mathrm{H}_{2}$ at atmospheric pressure (Enzell, 1962). Contaminating hydrocarbons were removed from the single oxygenated product by passing the mixture in hexane through a small silica 
gel column, then eluting the cis-dihydrowiddrol [(4aS,7S,9aS)-1,1,4a,7-

tetramethyldecahydro- $1 H$-benzo[7] annulen-7-ol] with 25\% EtOAc/hexane (yield ca. 20 mg). NMR: ${ }^{1} \mathrm{H}\left(500.13 \mathrm{MHz}, \mathrm{CDCl}_{3}\right.$, solv. ref. 7.26, $\delta$ from TMS): 0.89 (3H, $\left.s, \mathrm{H}-13\right)$, $1.00(3 \mathrm{H}, s, \mathrm{H}-12), 1.07(1 \mathrm{H}, d, J=10 \mathrm{~Hz}, \mathrm{H}-1), 1.10(3 \mathrm{H}, s, \mathrm{H}-15), 1.12(1 \mathrm{H}, m, \mathrm{H}-2 \beta)$, $1.13(1 \mathrm{H}, m, \mathrm{H}-8 \mathrm{~b}), 1.17$ (1H, $m, \mathrm{H}-10 \mathrm{~b}), 1.18$ (1H, $m, \mathrm{H}-6 \alpha), 1.24$ (3H, $s, \mathrm{H}-14), 1.35$ (2H, $m, \mathrm{H}-8 \mathrm{a}, \mathrm{H}-10 \mathrm{a}), 1.36(1 \mathrm{H}, m, \mathrm{H}-6 \beta), 1.41(1 \mathrm{H}, m, \mathrm{H}-3 \alpha), 1.46(1 \mathrm{H}, m, \mathrm{H}-9 \beta), 1.51$ $(1 \mathrm{H}, m, \mathrm{H}-5 \beta), 1.53(1 \mathrm{H}, m, \mathrm{H}-2 \alpha), 1.58(1 \mathrm{H}, q t, J=6.1,1.8 \mathrm{~Hz}, \mathrm{H}-9 \alpha), 1.76(1 \mathrm{H}, d d, J$ $=13.5,11.7 \mathrm{~Hz}, \mathrm{H}-5 \alpha), 1.87(1 \mathrm{H}, d d d, J=13.1,7.7,2.4 \mathrm{~Hz}, \mathrm{H}-3 \beta) ;{ }^{13} \mathrm{C} \mathrm{NMR}(125.77$ $\mathrm{MHz}, \mathrm{CDCl}_{3}$, solv. ref. 77.0, $\delta$ from TMS): $17.9(t, \mathrm{C}-9), 22.2(t, \mathrm{C}-2), 27.8(s, \mathrm{C}-14)$, 29.0 ( $s, \mathrm{C}-13), 30.3$ ( $s, \mathrm{C}-15), 32.1$ ( $s, \mathrm{C}-12), 34.4(s, \mathrm{C}-7), 35.1$ ( $t, \mathrm{C}-8), 35.6$ ( $t, \mathrm{C}-10)$, $36.4(s, \mathrm{C}-11), 37.1$ ( $t, \mathrm{C}-5), 39.8$ ( $t, \mathrm{C}-6), 46.0(t, \mathrm{C}-3), 55.3$ ( $d, \mathrm{C}-1), 73.2(s, \mathrm{C}-4)$; assignments by HMQC and HMBC, cis ring fusion confirmed by NOESY cross-peaks from $\mathrm{H}-15$ to $\mathrm{H}-12$ (both $\alpha$-oriented) and from $\mathrm{H}-12$ to $\mathrm{H}-1$, in reference to minimumenergy conformation determined by MM2 calculation. $10 \mathrm{mg}$ of cis-dihydrowiddrol was dehydrated for $1 \mathrm{hr}$ with 8 drops $\mathrm{POCl}_{3}$ in $0.3 \mathrm{ml}$ pyridine, excess $\mathrm{POCl}_{3}$ destroyed by adding ice, and the mixture of monoenes ( 2 isomers, ca. $4: 1$ ratio) extracted with pentane. About $2 \mathrm{mg}$ of the product hydrocarbon mix was directly hydrogenated with a catalytic amount of $\mathrm{PtO}_{2}$ in $0.4 \mathrm{ml} \mathrm{MeOH}$ for $2 \mathrm{hr}$, yielding 2 fully saturated epimers in ca. 2:1 ratio, with some of the major monoene remaining unreacted. $1 \mathrm{mg} 15$ was similarly hydrogenated, yielding 2 fully saturated epimers in ca. 1:1 ratio. Retention times of the widdrol-derived widdranes were identical with those from 15 on conventional dual-column GC but longer on EGC. 
Acknowledgements

I thank Robert Flath for a sample of authentic (-)-guaia-6,9-diene; Y. Venkateswarlu for MS data on guaia-6,10(15)-diene; Robert P. Adams for GC-MS data of $\alpha$-cuprenene; Eugene Zavarin for encouragement and helpful discussions; and Rudi Nunlist and Herman van Halbeek for their capable help with many of the 2D NMR experiments. I am especially grateful to David E. Cane for generously offering guidance in developing the biosynthetic scheme. Deo gratias. 


\section{References}

Ansari, H. R., 1973. Cyclisation of optically active dihydromyrcenes (2,6-dimethyl-2,7octadiene). Tetrahedron 29, 1559-1564.

Bernard, M., Canuel, C., St-Jacques, M., 1974. A comparative study of the rates and mechanisms of conformational interconversion in derivatives of cyclohexanone and methylenecyclohexane. JACS 96, 2929-2936.

Braun, N. A., Meier, M., Schmaus, G., Hölscher, B., Pickenhagen, W., 2003.

Enantioselectivity in odor perception: synthesis and olfactory properties of iso- $\beta$ bisabolol, a new natural product. Helv. Chim. Acta, 86, 2698-2708.

Briggs, L. H., Sutherland, M. D., 1942. The essential oil of Cupressus macrocarpa. J. Org. Chem. 7, 397-407.

Cane, D. E., 1981. Biosynthesis of sesquiterpenes. In: Porter, J. W. and Spurgeon, S. L. (Eds.), Biosynthesis of Isoprenoid Compounds. John Wiley and Sons, New York, pp. 283-374.

Cane, D. E., 1985. Isoprenoid biosynthesis. Stereochemistry of the cyclization of allylic pyrophosphates. Acc. Chem. Res. 18, 220-226. 
Cane, D. E., 1999. Sesquiterpene biosynthesis: cyclization mechanisms. In: Barton, D., Nakanishi, K., Meth-Cohn, O. (Eds.), Comprehensive Natural Products Chemistry, Vol. 2. Elsevier, Amsterdam, pp. 155-200.

Cool, L. G., 2001. ent-Daucane and acorane sesquiterpenes from $\times$ Cupressocyparis leylandii foliage. Phytochemistry 58, 969-972.

Daeniker, H. U., Hochstetler, A. R., Kaiser, K., Kitchens, G. C., 1972. The acidcatalyzed isomerization of thujopsene. J. Org. Chem. 37, 1-5.

Enzell, C., 1962. Chemistry of the natural order Cupressales. XLVII. Structure and absolute stereochemistry of widdrol and widdrol $\alpha$-epoxide. Acta Chem. Scand. 16, 1553-1568.

Erman, W. F., 1985. Chemistry of the monoterpenes : an encyclopedic handbook. Marcel Dekker, New York.

Ito, S., Endo, K., Narita, H., 1974. $\alpha$-Pseudowiddrene, a new sesquiterpene hydrocarbon from Thujopsis dolobrata. Tetrahedron Lett., 1041-1043.

Kaiser, R., Naegeli, P., 1972. Biogenetically significant components in vetiver oil. Tetrahedron Lett., 2009-2012. 
Kim, Y. K., Cool, L. G., Zavarin, E., 1994. cis-Calamenene-related sesquiterpenoids from Cupressus bakeri foliage. Phytochemistry 36, 961-965.

Marx, J. N., Norman, L. R., 1975. Synthesis of (-)-acorone and related spirocyclic sesquiterpenes. J. Org. Chem. 40, 1602-1606.

Mills, J. A., 1952. Correlations between monocyclic and polycyclic unsaturated compounds from molecular rotation differences. J. Chem. Soc., Abstracts, 4976-4985.

Nabeta, K., Ara, Y., Aoki, Y., Miyake, M., 1990. Biosynthesis of monoterpenes and sesquiterpenes in Larix leptolepis callus from deuterated mevalonates. J. Nat. Prod. 53, 1241-1248.

Nabeta, K., Kawakita, K., Yada, Y., Okuyama, H., 1993. Biosynthesis of sesquiterpenes from deuterated mevalonates in Perilla callus. Biosci. Biotech. Biochem. 57, 792-798.

Naegeli, P., Wetli, M., 1981. Cationic $\pi$-cyclisation of $\alpha, \beta$-unsaturated carbonyl compounds. Tetrahedron 37, Suppl. 1, 247-255. 
Rao, M. Rama, Sridevi, K. V., Venkatesham, U., Rao, T. Prabhaker, Lee, S. S., Venkateswarlu, Y., 2000. Four new sesquiterpenoids from the soft coral Nephthea chabrolii. J. Chem. Res., Synopses, 245-247.

Snowdon, R. L., Linder, S. M., Muller, B. L., Schulte-Elte, K. H., 1987. $\beta$-Cleavage of bis(homoallylic) potassium alkoxides. Two-step preparation of propenyl ketones from carboxylic esters. Synthesis of ar-turmerone, $\alpha$-damascone, $\beta$-damascone, and $\beta$ damascenone. Helv. Chim. Acta 70, 1858-1878.

Steele, C. L., Crock, J., Bohlmann, J., Croteau, R (1998). Sesquiterpene synthases from grand fir (Abies grandis). J. Biol. Chem. 273, 2078-2089.

Sy, L.-K., Brown, G. D., 1998. A sesquiterpene class from Illicium dunnianum. Phytochemistry 47, 301-302.

Tebayashi, S., Hirai, N., Suzuki, T., Matsuyama, S., Nakakita, H., Nemoto, T., Nakanishi, H., 1998. Identification of $(+)$-acoradiene as an aggregation pheromone for Gnatocerus cornutus (F.) (Coloptera: Tenebrionidae). J. Stored Prod. Res. 34, 99-106.

Tumlinson, J. H., Gueldner, R. C., Hardee, D. D., Thompson, A. C., Hedin, P. A., Minyard, J. P., 1971. Identification and synthesis of the four compounds comprising the boll weevil sex attractant. J. Org. Chem. 36, 2616-2621. 
Wolf, C. B., 1948. Taxonomic and distributional studies of the New World cypresses:

Cupressus macrocarpa. El Aliso 1, 181-193.

Zavarin, E., Lawrence, L., Thomas, M. C., 1971. Compositional variations of leaf

monoterpenes in Cupressus macrocarpa, C. pygmaea, C. goveniana, C. abramsiana

and C. sargentii. Phytochemistry 10, 379-393. 